\title{
Sagittal alignment and complications following lumbar 3-column osteotomy: does the level of resection matter?
}

\author{
Emmanuelle Ferrero, MD, MSc,, ${ }^{1,2}$ Barthelemy Liabaud, MD, ${ }^{2}$ Jensen K. Henry, MD, ${ }^{2}$ \\ Christopher P. Ames, MD, ${ }^{3}$ Khaled Kebaish, MD, ${ }^{4}$ Gregory M. Mundis, MD, ${ }^{5}$ Richard Hostin, MD, ${ }^{6}$ \\ Munish C. Gupta, MD, ${ }^{7}$ Oheneba Boachie-Adjei, MD, ${ }^{8}$ Justin S. Smith, MD, PhD, ${ }^{9}$ \\ Robert A. Hart, MD, ${ }^{10}$ lbrahim Obeid, MD, ${ }^{11}$ Bassel G. Diebo, MD, ${ }^{2}$ Frank J. Schwab, MD, ${ }^{2}$ and \\ Virginie Lafage, $\mathrm{PhD},{ }^{2}$ on behalf of the International Spine Study Group
}

${ }^{1}$ Hôpital Européen Georges-Pompidou, APHP, Paris V University, Paris, France; ²Department of Orthopaedic Surgery, Spine Division, Hospital for Special Surgery, New York, New York; ' ${ }^{D}$ epartment of Neurosurgery, University of California, San Francisco Medical Center, San Francisco, California; ${ }^{4}$ Department of Orthopaedic Surgery, Johns Hopkins University, Baltimore, Maryland; ${ }^{5}$ San Diego Center for Spinal Disorders, La Jolla, California; ${ }^{6}$ Baylor Scoliosis Center, Plano, Texas; ${ }^{7}$ Department of Orthopaedic Surgery, University of California, Davis, Sacramento, California; ${ }^{8}$ Department of Orthopedic Surgery, Hospital for Special Surgery, New York, New York; ' Department of Neurosurgery, University of Virginia Health System, Charlottesville, Virginia; ${ }^{10}$ Department of Orthopedic Surgery, University of Oregon Health Sciences Center, Portland, Oregon; and ${ }^{11}$ Centre Hospitalier Universitaire de Bordeaux, France

\begin{abstract}
OBJECTIVE Three-column osteotomy ( $3 \mathrm{CO})$ is a demanding technique that is performed to correct sagittal spinal malalignment. However, the impact of the $3 \mathrm{CO}$ level on pelvic or truncal sagittal correction remains unclear. In this study, the authors assessed the impact of $3 \mathrm{CO}$ level and postoperative apex of lumbar lordosis on sagittal alignment correction, complications, and revisions.
\end{abstract}

METHODS In this retrospective study of a multicenter spinal deformity database, radiographic data were analyzed at baseline and at 1- and 2-year follow-up to quantify spinopelvic alignment, apex of lordosis, and resection angle. The impact of $3 \mathrm{CO}$ level and apex level of lumbar lordosis on the sagittal correction was assessed. Logistic regression analyses were performed, controlling for cofounders, to investigate the effects of $3 \mathrm{CO}$ level and apex level on intraoperative and postoperative complications as well as on the need for subsequent revision surgery.

RESULTS A total of 468 patients were included (mean age 60.8 years, mean body mass index $28.1 \mathrm{~kg} / \mathrm{m}^{2}$ ); $70 \%$ of patients were female. The average $3 \mathrm{CO}$ resection angle was $25.1^{\circ}$ and did not significantly differ with regard to $3 \mathrm{CO}$ level. There were no significant correlations between the $3 \mathrm{CO}$ level and amount of sagittal vertical axis or pelvic tilt correction. The postoperative apex level significantly correlated with greater correction of pelvic tilt $\left(2^{\circ}\right.$ per more caudal level, $R=$ $-0.2, p=0.006)$. Lower-level $3 \mathrm{CO}$ significantly correlated with revisions for pseudarthrosis $(O R=3.88, p=0.001)$ and postoperative motor deficits $(O R=2.02, p=0.026)$.

CONCLUSIONS In this study, a more caudal lumbar $3 \mathrm{CO}$ level did not lead to greater sagittal vertical axis correction. The postoperative apex of lumbar lordosis significantly impacted pelvic tilt. $3 \mathrm{CO}$ levels that were more caudal were associated with more postoperative motor deficits and revisions.

https://thejns.org/doi/abs/10.3171/2017.3.SPINE16357

KEY WORDS 3-column osteotomy; adult spinal deformity; lumbar lordosis; sagittal alignment; complications

$\mathrm{A}$ DULT spinal deformity (ASD) is a debilitating disorder that is increasingly prevalent, especially in the elderly. ${ }^{1-4,10}$ ASD is often manifested by a loss of lumbar lordosis (LL) with anterior global malalignment, pelvic retroversion, and multiple attempts at com-

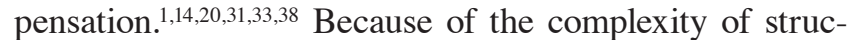
tural pathologies and clinical presentations, ASD correction remains challenging, thus underscoring the need for better evidence-based treatment. ${ }^{19,38}$

Surgical treatment of ASD requires sufficient resto-

ABBREVIATIONS ASD = adult spinal deformity; BMI = body mass index; $\mathrm{EBL}=$ estimated blood loss; $\mathrm{LL}=$ lumbar lordosis; $\mathrm{PI}=$ pelvic incidence; $\mathrm{PT}=$ pelvic tilt; $\mathrm{SVA}=$ sagittal vertical axis; TK = thoracic kyphosis; T1SPi = T-1 spinopelvic inclination; $3 \mathrm{CO}=3$-column osteotomy.

SUBMITTED March 30, 2016. ACCEPTED March 20, 2017.

INCLUDE WHEN CITING Published online September 8, 2017; DOI: 10.3171/2017.3.SPINE16357. 
ration of sagittal alignment to reset the compensatory mechanisms and improve the patient's functional status. The Scoliosis Research Society-Schwab deformity classification established key radiographic sagittal parameters with ideal thresholds for realignment in terms of sagittal vertical axis (SVA), pelvic incidence (PI) minus LL (i.e., PI-LL mismatch), and pelvic tilt (PT). ${ }^{13,22,39}$ The 3-column osteotomy (3CO) is a powerful method to correct fixed spinal deformity. $2,4,9,12,27,30,37,40,42,43$

Several studies have emphasized the importance of preoperative planning for sagittal realignment procedures. ${ }^{13,41}$ However, anticipating the postoperative alignment after 3CO remains challenging. ${ }^{13,25,32}$ Although the relationship between resection angle and sagittal correction is obvious, the relationship between the osteotomy level and sagittal correction remains controversial, with a belief that osteotomies that are more caudal lead to greater correction..$^{15,24}$ Lafage et al. reported that more caudal 3CO correlated with higher PT correction. ${ }^{24}$ Nevertheless, the impact of the level of osteotomy on the distribution of truncal versus pelvic correction remains unclear. ${ }^{8,24,44,45}$ To our knowledge, no reports exist regarding the relationship between the apex of LL and the degree of sagittal plane correction. In addition, while studies have reported complication rates after $3 \mathrm{CO}$ of up to $50 \%$ and revision surgery rates of up to $44 \%, 2,5,11,16,28$ little is known regarding the impact of osteotomy level on complications and revisions.

The purpose of the present study was to investigate the impact of the osteotomy level and postoperative lordosis apex on sagittal correction and to assess for potential associations between the level of $3 \mathrm{CO}$ and complication and revision rates. It was hypothesized that the apex of LL plays a significant role in sagittal plane correction following $3 \mathrm{CO}$ and that caudal osteotomies will be associated with a higher risk of complications.

\section{Methods}

\section{Patient Selection}

This is a retrospective multicenter database of patients who underwent $3 \mathrm{CO}$ for sagittal plane malalignment. The institutional review board at each contributing site provided approval prior to study initiation. The study included patients older than 18 years who underwent a single lumbar 3CO for lumbar deformity and an upper instrumented vertebral level above L-1. Exclusion criteria were spinal deformity due to neuromuscular etiology, thoracic $3 \mathrm{CO}$, and more than one $3 \mathrm{CO}$.

\section{Data Collection}

Demographic parameters included age, sex, and body mass index (BMI). Full-spine radiographs were obtained at baseline and at 1 and 2 years postoperatively. Surgical parameters included 3CO level, operating room time, and estimated blood loss (EBL). Intraoperative and postoperative complications were recorded, along with incidence and timing of revision surgery (up to 2 years postoperatively).

\section{Radiographic Measurement}

Radiographs were analyzed using validated software

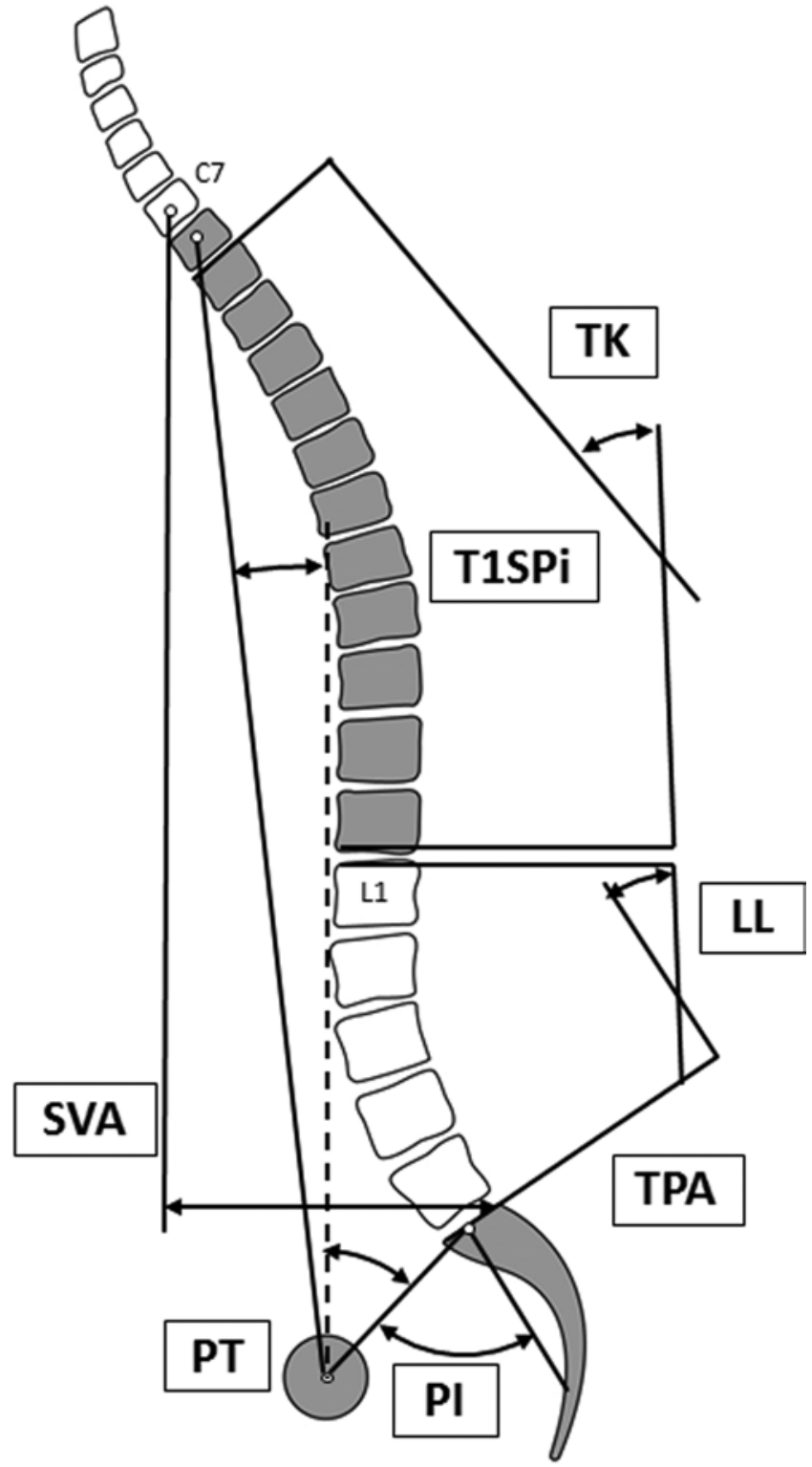

FIG. 1. Sagittal radiographic parameters, including SVA, LL, PI, PT, T1SPi, and TK. TPA = T-1 pelvic angle.

(Spineview, ENSAM Paris-Tech). ${ }^{34}$ Sagittal spinopelvic radiographic parameters included cervical lordosis, T2-12 thoracic kyphosis (TK), LL, PI-LL mismatch, and pelvic parameters (PI, PT, and sacral slope). ${ }^{46}$ Global sagittal alignment parameters included SVA and T-1 spinopelvic inclination (T1SPi) (Fig. 1). The $3 \mathrm{CO}$ resection angle was defined as the change in the angle formed by the upper endplate of the vertebra below the $3 \mathrm{CO}$ and the lower endplate of the vertebra above the $3 \mathrm{CO}$. Change in LL outside the osteotomy site (LL outside 3CO) was calculated as the difference between LL and the $3 \mathrm{CO}$ resection angle. The apex of the postoperative lordosis (apex level) was defined as the lumbar vertebra that was most anteriorly displaced from the L1-S1 line (midpoint of L-1 upper endplate to midpoint of S-1 upper endplate) (Fig. 2). 


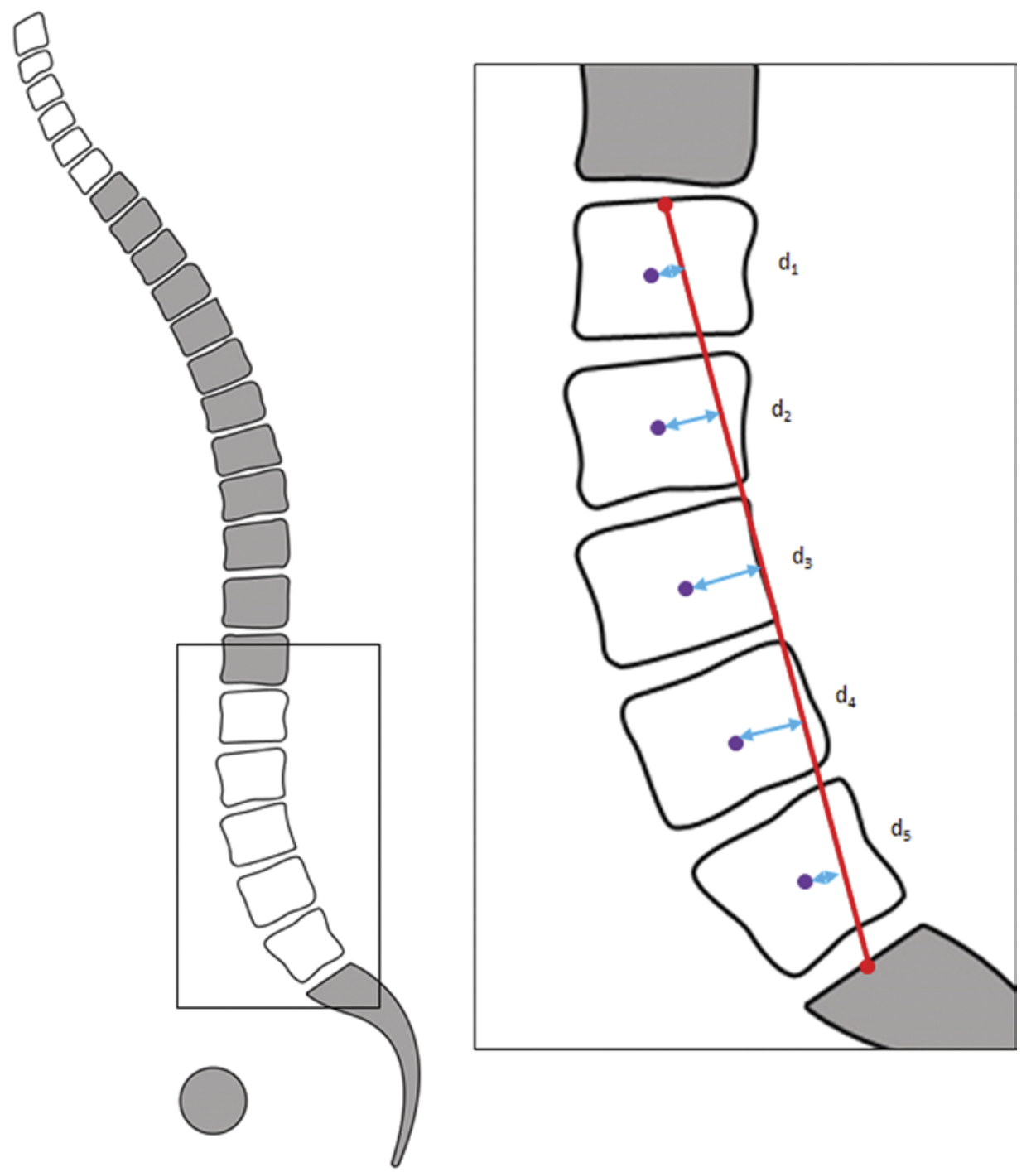

FIG. 2. Illustration of the apex of LL. A line is drawn between the midpoint of the upper endplate of L-1 and the midpoint of the upper endplate of S-1. The orthogonal distance (d) between this line and the center of each lumbar vertebral body was calculated; the vertebra with the largest distance was considered the apex of LL. Figure is available in color online only.

\section{Statistical Analysis}

Normality of distribution was confirmed using the Shapiro-Wilk test. Descriptive statistics were used to show demographic and surgical characteristics. Baseline and postoperative radiographic parameters were compared using paired t-tests. Pearson tests were used to correlate the 3CO resection angle and changes in radiographic parameters. Spearman tests assessed relationships between $3 \mathrm{CO}$ level, LL apex level, and sagittal correction. Multivariate regression was used to analyze the relationship between 3CO level and LL apex level on changes in radiographic parameters, using the potential confounders of baseline PT, TK, LL, and SVA. Complications and revisions were compared between $3 \mathrm{CO}$ levels using the chi-square test. Multivariate regression was performed to assess the impact of 3CO level on complications and revisions, adjusting for age, BMI, and resection angle. Patients who underwent revision surgery before 1 year were excluded from radiographic analysis to avoid potential effects of revision surgery on sagittal alignment. Statistical analysis was performed using Stata software (version 13.0, StataCorp). A $\mathrm{p}$ value $<0.05$ was considered significant.

\section{Results}

This study included 468 patients $(70 \%$ of whom were female) with a mean age of $60.8 \pm 11.0$ years and a mean BMI of $28.1 \pm 7.1 \mathrm{~kg} / \mathrm{m}^{2}$. At baseline, $393(84 \%)$ of the patients had a history of previous spine surgery.

\section{Radiographic Alignment}

A total of 345 patients had at least 1 year of follow-up and were included in the radiographic cohort. The most common 3CO levels were L-3 (47\%) and L-4 (25\%). The mean resection angle was $25.1^{\circ} \pm 12.7^{\circ}$, with no significant differences across $3 \mathrm{CO}$ levels ( $\mathrm{p}=0.45$; Table 1$)$. All sagit- 
TABLE 1. 3CO levels and amount of focal correction in the radiographic cohort

\begin{tabular}{ccc}
\hline 3CO Level & No. of Patients (\%) & Mean Resection Angle $\left({ }^{\circ}\right)^{*}$ \\
\hline L-1 & $23(7)$ & $28.9 \pm 12.9$ \\
\hline L-2 & $62(18)$ & $23.0 \pm 13.9$ \\
\hline L-3 & $163(47)$ & $25.6 \pm 12.1$ \\
\hline L-4 & $86(25)$ & $25.4 \pm 13.2$ \\
\hline L-5 & $11(3)$ & $20.3 \pm 11.8$ \\
\hline
\end{tabular}

* The mean resection angle was not significantly associated with $3 \mathrm{CO}$ level.

tal parameters, aside from cervical lordosis, demonstrated significant improvement postoperatively (Table 2). There were significant improvements in LL $\left(29.3^{\circ}\right)$, PT $\left(-7.5^{\circ}\right)$, PI-LL $\left(-29.4^{\circ}\right)$, and SVA $(-99.1 \mathrm{~mm})$. The mean change in LL outside the $3 \mathrm{CO}$ was $5.9^{\circ} \pm 14.2^{\circ}$.

For patients treated with $3 \mathrm{CO}$ at L-1, L-2, L-4, or L-5, the most common postoperative apex level was L-4 (70\%, $50 \%, 50 \%$, and $53 \%$, respectively). For L-3 3CO, the most common postoperative apex level was L-3 (76\%) (see Fig. 3 for the distribution of $3 \mathrm{CO}$ and apex levels). Figure 4 illustrates the differences between LL apex and 3CO level pre- and postoperatively. The postoperative LL apex was closer to the 3CO level than the preoperative LL apex. Correlation analysis (Table 3) revealed that the $3 \mathrm{CO}$ resection angle correlated with changes in LL, TK, PT, and SVA. Change in LL outside of the $3 \mathrm{CO}$ correlated with change in PT and change in global alignment. Apex level correlated with change in PT $(\mathrm{R}=-0.175, \mathrm{p}<0.05)$. Of patients with $3 \mathrm{CO}$ resection $\geq 15^{\circ}$, the correlation between apex level and change in PT was $\mathrm{R}=0.228$. Of patients with $3 \mathrm{CO}$ resection $\geq 25^{\circ}$, the correlation increased to $\mathrm{R}$ $=0.238$.

Multivariate analysis demonstrated that PT correction increased with a more caudal lordosis apex $\left(-2.03^{\circ}\right.$ of additional PT correction per each level below L-1; $\mathrm{p}=$ $0.004)$. No similar relationship was found based on $3 \mathrm{CO}$ level (Table 4). LL correction and baseline sagittal parameters were significant parameters involved in the change in PT and SVA, suggesting that patients with more severe preoperative deformity severity experienced greater corrections in PT and SVA. Only LL correction and baseline SVA were significant parameters influencing change in the T1SPi.

\section{Complications}

Overall, $40 \%$ of patients had major complications (either intra- or early postoperative) (Table 5). The intraoperative complication rate was $20 \%(n=93)$. Intraoperative EBL of more than $4 \mathrm{~L}$ was the most common intraoperative complication, occurring in $18 \%$ of cases $(n=83)$. Less common intraoperative complications were intraoperative cord deficit $(\mathrm{n}=3 ; 1 \%)$, intraoperative nerve root injury $(n=4 ; 1 \%)$, and unplanned staged surgery $(n=3 ; 1 \%)$. Intraoperative complication rates did not differ significantly based on $3 \mathrm{CO}$ level.

The overall 6-week postoperative complication rate was $27 \%(\mathrm{n}=128)$. Complications differed significantly based on $3 \mathrm{CO}$ level. Postoperative complications were
TABLE 2. Mean baseline and 1-year postoperative sagittal radiographic parameters

\begin{tabular}{lcccc}
\hline \multicolumn{1}{c}{ Parameter } & Preop & Postop & Change & p Value \\
\hline PI & $59.5 \pm 15.3$ & & & \\
\hline PT & $31.5 \pm 10.8$ & $24.5 \pm 10.4$ & $-7.5 \pm 8.6$ & $<0.001$ \\
\hline PI-LL & $33.7 \pm 20.5$ & $5.2 \pm 16.3$ & $-29.4 \pm 18.2$ & $<0.001$ \\
\hline LL & $25.3 \pm 20.6$ & $54.6 \pm 14.3$ & $+29.3 \pm 18.1$ & $<0.001$ \\
\hline TK & $31.8 \pm 21.3$ & $47.7 \pm 17.4$ & $+16.2 \pm 15.9$ & $<0.001$ \\
\hline SVA (mm) & $138.7 \pm 78.2$ & $42.2 \pm 56.3$ & $-99.1 \pm 70.6$ & $<0.001$ \\
\hline T1SPi & $4.2 \pm 7.4$ & $-3.5 \pm 5.2$ & $-7.7 \pm 7.0$ & $<0.001$ \\
\hline Cervical lordosis* & $18.1 \pm 18.9$ & $16.8 \pm 16.8$ & $-2.9 \pm 14.5$ & NS \\
\hline
\end{tabular}

NS = not significant.

All measurements are in degrees unless otherwise noted. Boldface type indicates statistical significance from preoperative to postoperative.

* $\mathrm{C} 2-7$.

most common after L-5 osteotomies (47\% of $3 \mathrm{CO}$ at L-5, $\mathrm{p}=0.047$ ). However, regression analysis did not reveal a significant impact between caudal 3CO and postoperative complications. In terms of specific complication rates, bowel/bladder deficit occurred in 3\% $(\mathrm{n}=16)$ of patients, postoperative cauda equina deficit in $0.6 \%(\mathrm{n}=3)$, postoperative deep infection in $4 \%(n=20)$, and postoperative unplanned return to the operating room in $10 \%(\mathrm{n}=48)$. There were no significant differences in these complication rates based on osteotomy level $(p>0.05)$. Postoperative motor deficits occurred in $8 \%(\mathrm{n}=39)$ of patients, with significantly different rates based on 3CO level $(\mathrm{p}=$ $0.03)$. Regression analysis showed a significantly greater risk of motor deficits with more caudal $3 \mathrm{CO}(\mathrm{OR}=2.02$, $\mathrm{p}=0.026)$.

\section{Revisions}

Within 1 year, $18 \%$ of patients $(n=84)$ underwent revision surgery; 8 of these 84 patients had 2 revision surgeries (Table 5). Logistic regression analysis demonstrated a significantly greater risk of revision in the 1st year when the $3 \mathrm{CO}$ was performed at a more caudal level $(\mathrm{OR}=1.67$, $p=0.009)$. Revision was indicated for instrumentation failure in $6 \%$ of patients $(\mathrm{n}=26)$, for proximal junctional kyphosis in $3 \%(\mathrm{n}=13)$, for sagittal malalignment in $2 \%$ $(n=7)$, and for neurological deficit in 3\% $(n=14)$. There were no significant differences in these complication rates based on osteotomy level ( $\mathrm{p}>0.05$ ). Pseudarthrosis occurred within the 1st year in $3 \%$ of patients $(\mathrm{n}=16)$ and occurred in patients with a $3 \mathrm{CO}$ at L-3, L-4, or L-5. Regression analysis demonstrated a significantly greater risk of pseudarthrosis with a more caudal $3 \mathrm{CO}$ level $(\mathrm{OR}=$ $3.88, \mathrm{p}=0.001)$.

\section{Discussion}

In this study, more caudal lumbar 3CO did not lead to greater SVA or PT correction, although a more caudal postoperative apex of LL was associated with greater PT correction. However, 3CO levels that were more caudal were also associated with higher rates of complications and revisions. We found a mean amount of 3CO resec- 


$$
60 \%
$$

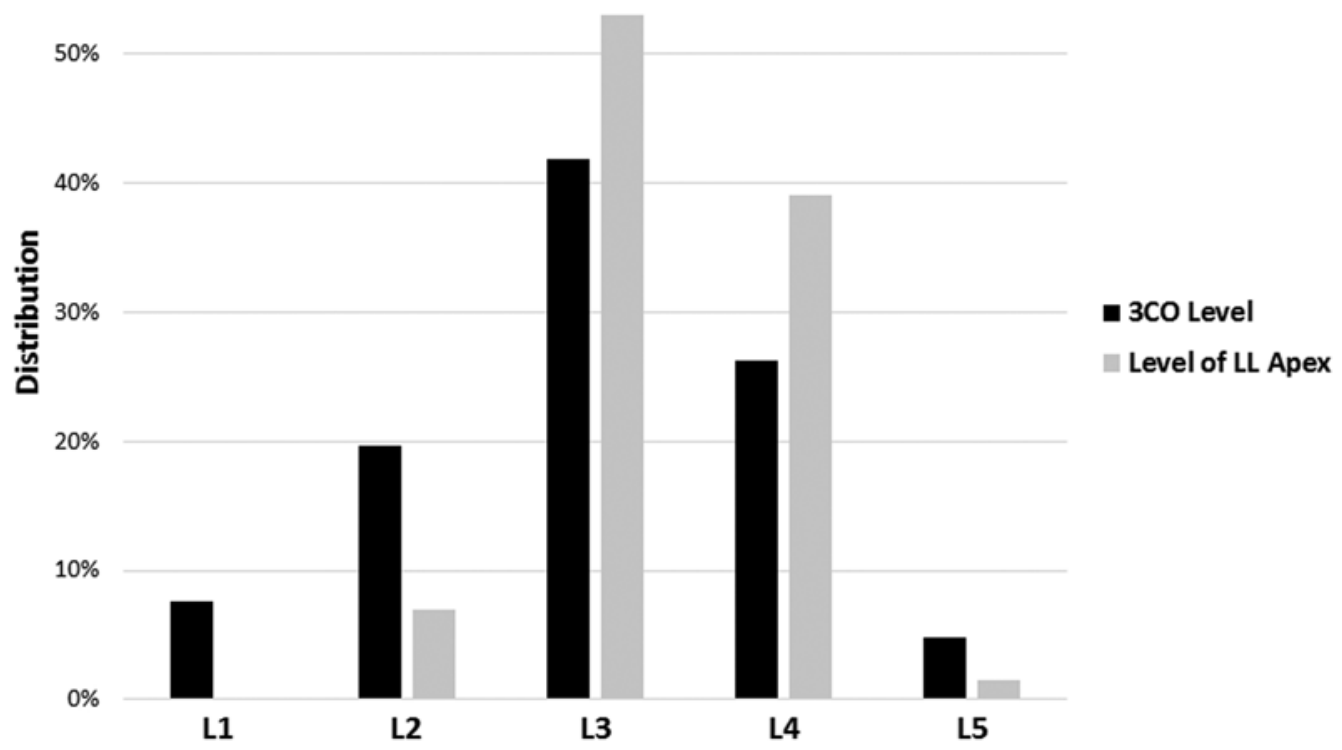

FIG. 3. Distribution of $L L$ apex and $3 C O$ levels for the entire cohort.

tion of $25.1^{\circ}$, which was similar across vertebral levels. This resection amount is comparable to that in other $3 \mathrm{CO}$ studies. $7,24,35,47$ Unsurprisingly, the $3 \mathrm{CO}$ resection directly impacted the regional LL with a mean LL correction of $29.3^{\circ}$. However, the indirect impact of the $3 \mathrm{CO}$ resection extended to the thoracic spine, with a $16.2^{\circ}$ increase in TK. This may have been due to direct changes by instru- mentation as well as reciprocal changes in the unfused thoracic spine, which is consistent with previous reports. ${ }^{18,22}$ Increase in LL led to improvement in the global alignment of the spine, characterized by decreases in SVA and pelvic retroversion (PT). This was confirmed by the correlation between angle of resection and improvement in radiographic parameters at the 1-year follow-up. This

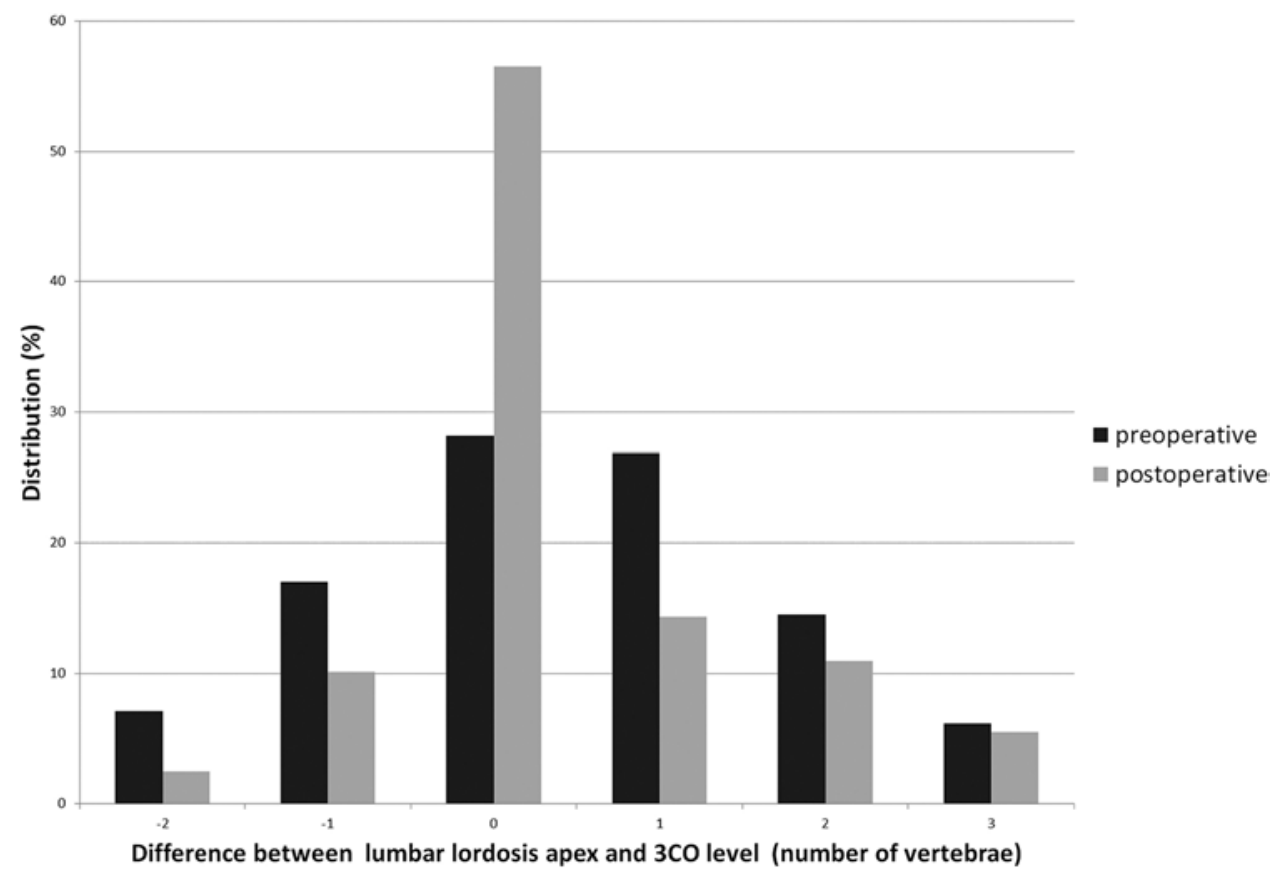

FIG. 4. Distribution of the difference between LL apex and $3 C O$ level pre- and postoperatively. For the values on the $x$-axis, " 0 " indicates that the LL apex and the 3CO level are located at the same level; "-1," that the LL apex is located 1 vertebra above the $3 \mathrm{CO}$ level; "+1," that the LL apex is located 1 vertebra below the $3 \mathrm{CO}$ level, and so on. 
TABLE 3. Significant correlations between the angle of resection, $3 \mathrm{CO}$ level, LL apex, and change in sagittal parameters from baseline to 1 year postoperatively*

\begin{tabular}{lcccccc}
\hline \multicolumn{1}{c}{ Variable } & $\Delta(\mathrm{PI}-\mathrm{LL})$ & $\Delta \mathrm{PT}$ & $\Delta \mathrm{SVA}$ & $\Delta \mathrm{T} 1 \mathrm{SPi}$ & $\Delta \mathrm{LL}$ & $\Delta \mathrm{TK}$ \\
\hline $\begin{array}{l}\text { 3CO resection } \\
\text { angle }\end{array}$ & -0.480 & -0.230 & -0.180 & & 0.496 & 0.471 \\
\hline$\Delta \mathrm{LL}$ outside 3CO & -0.600 & -0.354 & -0.509 & -0.388 & 0.577 & \\
\hline 3CO level & & & & & & \\
\hline Apex level & & -0.175 & & & & \\
\hline
\end{tabular}

* Pearson correlation was used for $3 \mathrm{CO}$ resection angle and $\Delta \mathrm{LL}$ outside $3 \mathrm{CO}$. Spearman correlation was used for both $3 \mathrm{CO}$ and apex levels.

study illustrated that an increasing degree of $3 \mathrm{CO}$ resection resulted in greater changes in regional alignment as well as global sagittal alignment. ${ }^{24}$ This is also consistent with previous reports demonstrating the effect of spinal osteotomies in restoring sagittal alignment of the spine in the setting of ASD (Fig. 5).,2,21,30,37

Initial studies suggested that the amount of vertebral resection needed to achieve optimal spinal realignment can be predicted based on the C-7 plumb line, PI, and $3 \mathrm{CO}$ level. ${ }^{13,15}$ However, more recent work demonstrated that the degree of wedge resection correlated more closely with spinopelvic parameter correction than $3 \mathrm{CO}$ level. ${ }^{24,36}$ The authors also established that there was no correlation between 3CO level and SVA correction. ${ }^{23}$ The present study similarly demonstrated that there were no correlations between 3CO level and changes in spinopelvic or global sagittal parameters. This result echoes the findings of Rousseau et al., who studied 356 patients undergoing $3 \mathrm{CO}$ for the treatment of ASD. ${ }^{35,36}$ Their results demonstrated no significant impact of pedicle subtraction osteotomy level on postoperative PT or T1SPi. One specific finding of the current study relates to the correlation between change in PT and location of the postoperative apex
TABLE 5. Different types of complications, global rate, and results of ANOVA of the difference between osteotomy level

\begin{tabular}{ccc}
\hline Complication & Complication Rate & p Value \\
\hline Intraop complication & 0.20 & 0.46 \\
\hline Cord deficit & 0.01 & 0.05 \\
\hline Nerve root injury & 0.01 & 0.88 \\
\hline EBL $>4$ L & 0.18 & 0.65 \\
\hline Unplanned stage & 0.01 & 0.89 \\
\hline Postop complication & 0.27 & 0.04 \\
\hline Bowel/bladder deficit & 0.03 & 0.82 \\
\hline Cauda equina & 0.006 & 0.89 \\
\hline Deep infection & 0.04 & 0.65 \\
\hline Motor deficit & 0.08 & 0.03 \\
\hline Unplanned surgery & 0.10 & 0.59 \\
\hline Revision & 0.18 & 0.06 \\
\hline Instrumentation failure & 0.06 & 0.10 \\
\hline Pseudarthrosis & 0.08 & 0.04 \\
\hline PJK & 0.03 & 0.11 \\
\hline Sagittal malalignment & 0.015 & 0.19 \\
\hline Neurological deficit & 0.03 & 0.56 \\
\hline PJK & &
\end{tabular}

PJK = proximal junctional kyphosis.

Boldface type indicates statistical significance.

of the lumbar curve $(\mathrm{R}=-0.175, \mathrm{p}<0.05)$. This relationship was maintained even after controlling for cofactors (preoperative PT, SVA, TK, and LL). PT decreased $2^{\circ}$ for each level of LL apex that was more caudal. This could be explained by the change in the distribution of mass above the pelvis, which affects pelvic retroversion. Altogether, these results suggested that the extent of global spinal alignment and pelvic retroversion correction is affected by the osteotomy resection. The proportion of truncal versus PT correction has not been well described. Previous

TABLE 4. Results of the multivariate analysis demonstrating the impact of the $3 C 0$ level and postoperative LL apex on change in PT, T1SPi, and SVA

\begin{tabular}{|c|c|c|c|c|c|c|c|c|}
\hline \multirow[b]{2}{*}{ Dependent Variable } & \multirow[b]{2}{*}{$\mathrm{R}^{2}$} & \multicolumn{2}{|c|}{ Independent Variables } & \multicolumn{5}{|c|}{ Confounders ${ }^{*}$} \\
\hline & & 3CO Level & Apex Level & $\Delta \mathrm{LL}$ & PT & TK & LL & SVA \\
\hline$\Delta \mathrm{PT}$ & 0.501 & & & & & & & \\
\hline$p$ value & & 0.86 & 0.004 & $<0.001$ & $<0.001$ & 0.007 & 0.88 & $<0.001$ \\
\hline Beta coefficient & & -0.01 & -0.14 & -0.65 & -0.30 & 0.16 & -0.01 & 0.21 \\
\hline Coefficient & & -0.08 & -2.03 & -0.32 & -0.23 & 0.06 & -0.01 & 0.02 \\
\hline$\Delta \mathrm{T} 1 \mathrm{SPi}$ & 0.541 & & & & & & & \\
\hline$p$ value & & 0.15 & 0.77 & $<0.001$ & 0.027 & 0.12 & 0.11 & $<0.001$ \\
\hline Beta coefficient & & 0.69 & -0.01 & -0.36 & 0.11 & 0.09 & -0.12 & -0.65 \\
\hline Coefficient & & 0.49 & -0.15 & -0.13 & 0.07 & 0.03 & -0.04 & -0.06 \\
\hline$\triangle S V A$ & 0.601 & & & & & & & \\
\hline$p$ value & & 0.37 & 0.11 & $<0.001$ & 0.036 & 0.049 & 0.036 & $<0.001$ \\
\hline Beta coefficient & & 0.04 & -0.07 & -0.51 & 0.10 & 0.10 & -0.15 & -0.59 \\
\hline Coefficient & & 3.04 & -8.31 & -2.06 & 0.62 & 0.33 & -0.52 & -0.55 \\
\hline
\end{tabular}

Boldface type indicates statistical significance.

* Confounders were controlled. 


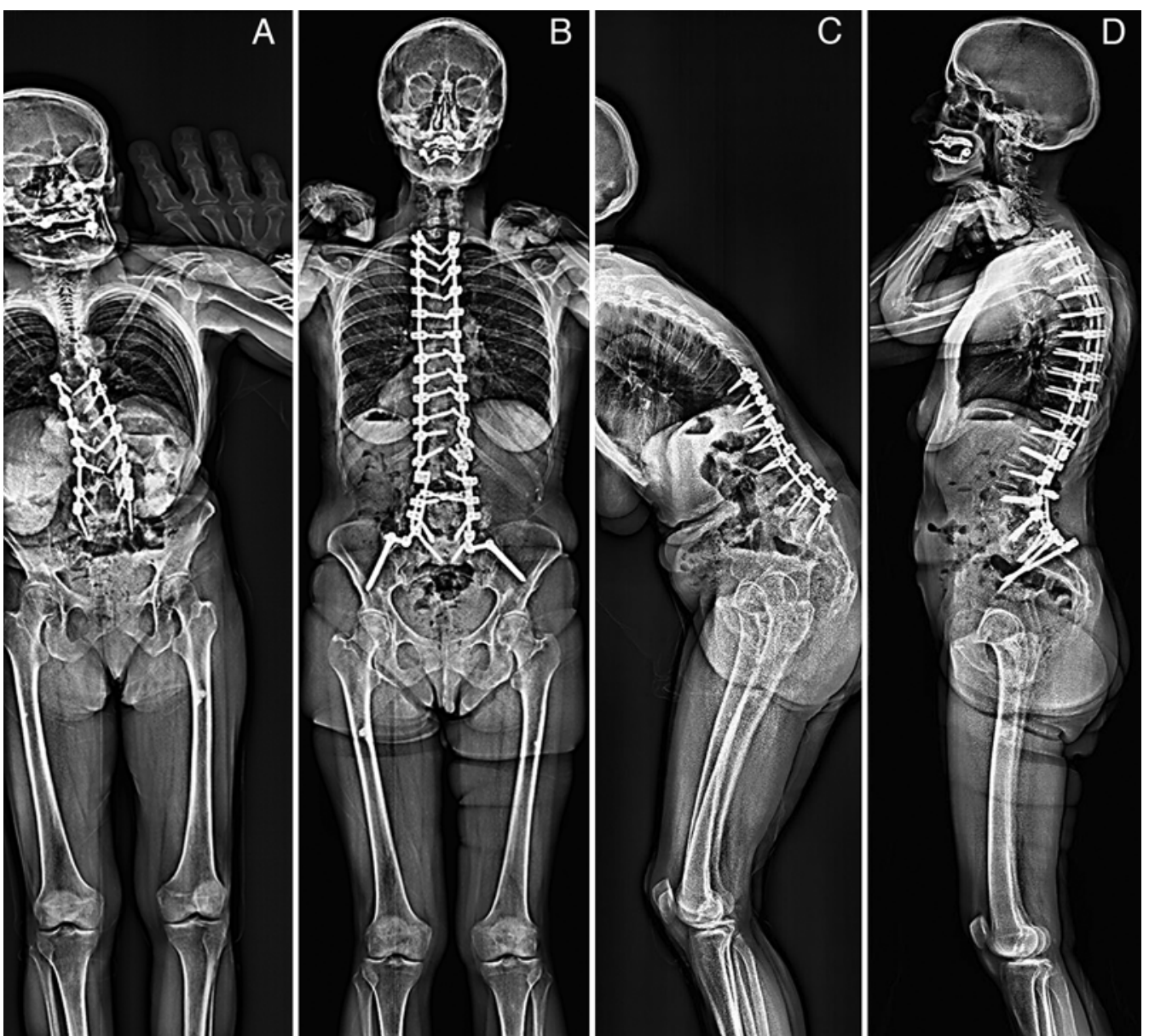

FIG. 5. Preoperative (A and $C$ ) and 1-year postoperative (B and $D)$ anteroposterior $(A$ and $B)$ and lateral $(C$ and $D)$ radiographs obtained in a 65-year-old patient with lumbar $3 \mathrm{CO}$ and major sagittal plane correction. At baseline, the patient had severe sagittal malalignment, with a PT of $26.7^{\circ}, \mathrm{PI}-\mathrm{LL}$ of $54.3^{\circ}$, and SVA of $345.6 \mathrm{~mm}$. At 1 year postoperatively, the measurements improved to a PT of $19.8^{\circ}$, PI-LL of $-9.7^{\circ}$, and SVA of $1.1 \mathrm{~mm}$.

studies have demonstrated varying proportions of trunk versus pelvic correction based on the spinal pathology and ankylosis. ${ }^{27,36}$ While there were correlations between LL correction outside the $3 \mathrm{CO}$ and correction of sagittal parameters, this study found no correlation between $3 \mathrm{CO}$ and change in radiographic parameters. This could indicate that the $3 \mathrm{CO}$ is not the only factor in correction surgery that leads to global realignment. Other factors such as facet resection, interbody cages, and reciprocal alignment changes in unfused segments may contribute to sagittal alignment changes. These hypotheses warrant future focused analyses.

In this study the complication rate was $41 \%$, which is consistent with rates in other published reports. Charosky et al. and Maier et al. reported complication rates ranging from $37 \%$ to $59 \%$ in the setting of ASD surgery. 5,28 In the current study, while the $3 \mathrm{CO}$ level was not associated with intraoperative complications, osteotomies that were more caudal were associated with increased early (6-week) postoperative complications and motor deficits. This could be due to the complex anatomy of the roots and lumbar plexus at the more caudal levels. Consequently, the potential risk for stretching the lumbar plexus should be considered. The postoperative motor deficit rate of $9 \%$, corresponding with the occurrence of a new deficit that was observed when the patient was awake after surgery but was not detected intraoperatively (with neuromonitoring or with obvious nerve root injury), was comparable to the previously reported rate of $7.5 \% .{ }^{5}$ Of note, decompression was performed during $3 \mathrm{CO}$ surgery if stenosis was seen on preoperative images (CT scans and MR images) and if there was a concordance between clinical symptoms and radiological images.

In this study, the revision rate was $18 \%$ in the 1 st year after $3 \mathrm{CO}$. This is also consistent with previous authors' findings of reoperation rates of $14 \%-20 \%$ in the same time period. ${ }^{6,17,29}$ Regarding mechanical complications, only revisions for pseudarthrosis were related to the $3 \mathrm{CO}$ level, with a higher rate for the more caudal osteotomy levels (Fig. 6). However, considering the small number of 3 COs performed at L-5 $(n=11)$, these significant results need to be interpreted with caution. Nevertheless, these findings suggest the need for an excellent anchor in the lumbosacral area, as well as the importance of posterolateral bone graft.

The strengths of this study include the large number of 

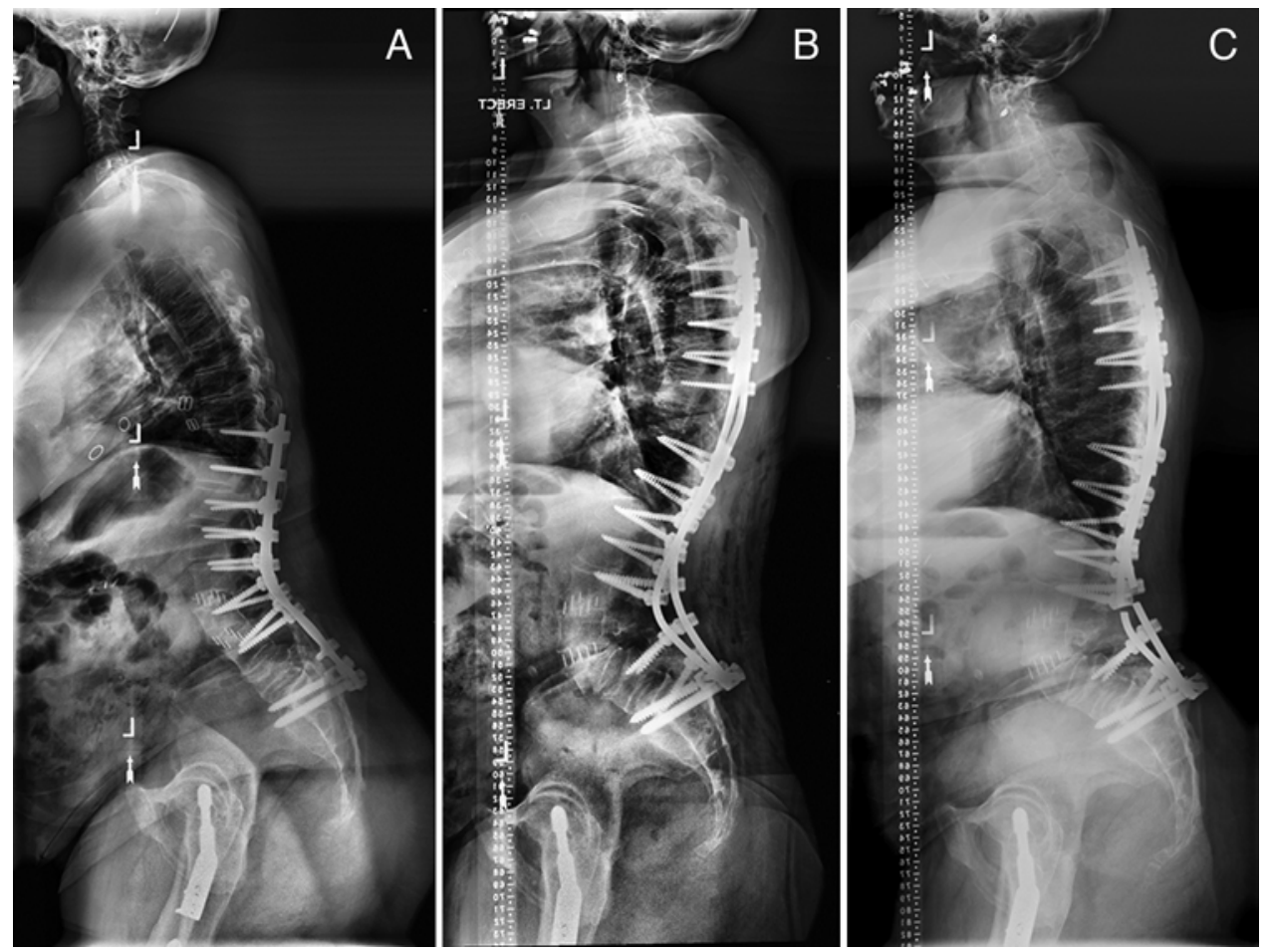

FIG. 6. Case example of a patient with a caudal $3 \mathrm{CO}(\mathrm{L}-4)$ who developed implant failure and pseudarthrosis necessitating revision before 1 year. Baseline (A), early postoperative (3 months; B), and 1-year postoperative $(\mathbf{C})$ radiographs are shown.

patients with lumbar 3CO levels and thresholds for fusion (i.e., only cases with an upper instrumented vertebra above L-1). Limitations of the study design include its retrospective nature and the consequences involved. Moreover, hip pathology and its influence on rotation of the pelvis around the hip were not studied and could potentially explain the limitations of pelvic retroversion in some cases. These issues could be addressed with hip radiographic analysis and dynamic radiography of the spine, along with soft-tissue analysis, in future studies. This study is further limited by the absence of patient-reported outcomes. Finally, assessment of additional intraoperative factors such as bone morphogenetic protein and implant type or number of rods were not assessed.

\section{Conclusions}

3CO is an effective but demanding technique to correct sagittal spinal malalignment. The current study demonstrated that resection angle and restoration of the postoperative lumbar apex to more caudal levels had a significant impact on PT correction. Restoration of the lumbar lordotic apex appears to have a great impact on spinopelvic alignment and is not necessarily equivalent to the osteotomy level. Moreover, the change in LL outside of the $3 \mathrm{CO}$ correlated with change in sagittal alignment. This suggests that $3 \mathrm{CO}$ level is not the only factor influencing truncal or pelvic correction.

In addition, the complication rate was important after 3CO surgery. The intraoperative complication rate did not differ based on 3CO level. However, the postoperative complication rate was higher with more caudal $3 \mathrm{CO}$ levels, especially for complications due to pseudarthrosis and new motor deficits. Consequently, the anatomy of lumbar nerve roots and a strong distal anchor should be considered. Further work on optimal LL apex location and predictive modeling could help surgeons better plan their complex realignment operations based on individual patients' sagittal alignment.

\section{References}

1. Bess S, Line B, Fu KM, McCarthy I, Lafage V, Schwab F, et al: The health impact of symptomatic adult spinal deformity: comparison of deformity types to United States population norms and chronic diseases. Spine (Phila Pa 1976) 41:224233, 2016

2. Boachie-Adjei O, Ferguson JA, Pigeon RG, Peskin MR: Transpedicular lumbar wedge resection osteotomy for fixed sagittal imbalance: surgical technique and early results. Spine (Phila Pa 1976) 31:485-492, 2006

3. Bridwell KH, Lewis SJ, Edwards C, Lenke LG, Iffrig TM, Berra A, et al: Complications and outcomes of pedicle subtraction osteotomies for fixed sagittal imbalance. Spine (Phila Pa 1976) 28:2093-2101, 2003

4. Bridwell KH, Lewis SJ, Lenke LG, Baldus C, Blanke K: Pedicle subtraction osteotomy for the treatment of fixed sagittal imbalance. J Bone Joint Surg Am 85-A:454-463, 2003

5. Charosky S, Guigui P, Blamoutier A, Roussouly P, Chopin $\mathrm{D}$ : Complications and risk factors of primary adult scoliosis surgery: a multicenter study of 306 patients. Spine (Phila Pa 1976) 37:693-700, 2012

6. Charosky S, Moreno P, Maxy P: Instability and instrumentation failures after a PSO: a finite element analysis. Eur Spine J 23:2340-2349, 2014

7. Cho KJ, Bridwell KH, Lenke LG, Berra A, Baldus C: Com- 
parison of Smith-Petersen versus pedicle subtraction osteotomy for the correction of fixed sagittal imbalance. Spine (Phila Pa 1976) 30:2030-2038, 2005

8. Dawson CW: Posterior elementectomy in ankylosing arthritis of the spine. Clin Orthop 10:274-281, 1957

9. Denis F: The three column spine and its significance in the classification of acute thoracolumbar spinal injuries. Spine (Phila Pa 1976) 8:817-831, 1983

10. During J, Goudfrooij H, Keessen W, Beeker TW, Crowe A: Toward standards for posture. Postural characteristics of the lower back system in normal and pathologic conditions. Spine (Phila Pa 1976) 10:83-87, 1985

11. Farcy JP, Schwab F: Posterior osteotomies with pedicle substraction for flat back and associated syndromes. Technique and results of a prospective study. Bull Hosp Jt Dis 59:1116,2000

12. Farcy JP, Schwab FJ: Management of flatback and related kyphotic decompensation syndromes. Spine (Phila Pa 1976) 22:2452-2457, 1997

13. Faundez A, Byrne F, Sylvestre C, Lafage V, Cogniet A, Le Huec JC: Pedicle subtraction osteotomy in the thoracic spine and thoracolumbar junction: a retrospective series of 28 cases. Eur Spine J 24 (Suppl 1):S42-S48, 2015

14. Glassman SD, Bridwell K, Dimar JR, Horton W, Berven S, Schwab F: The impact of positive sagittal balance in adult spinal deformity. Spine (Phila Pa 1976) 30:2024-2029, 2005

15. Goel A, Shah A, Jadhav M, Nama S: Distraction of facets with intraarticular spacers as treatment for lumbar canal stenosis: report on a preliminary experience with 21 cases. J Neurosurg Spine 19:672-677, 2013

16. Ikenaga M, Shikata J, Takemoto M, Tanaka C: Clinical outcomes and complications after pedicle subtraction osteotomy for correction of thoracolumbar kyphosis. J Neurosurg Spine 6:330-336, 2007

17. Kim YJ, Bridwell KH, Lenke LG, Cheh G, Baldus C: Results of lumbar pedicle subtraction osteotomies for fixed sagittal imbalance: a minimum 5-year follow-up study. Spine (Phila Pa 1976) 32:2189-2197, 2007

18. Klineberg E, Schwab F, Ames C, Hostin R, Bess S, Smith JS, et al: Acute reciprocal changes distant from the site of spinal osteotomies affect global postoperative alignment. Adv Orthop 2011:415946, 2011

19. Kobayashi T, Atsuta Y, Takemitsu M, Matsuno T, Takeda $\mathrm{N}$ : A prospective study of de novo scoliosis in a community based cohort. Spine (Phila Pa 1976) 31:178-182, 2006

20. Kostuik JP, Bentivoglio J: The incidence of low-back pain in adult scoliosis. Spine (Phila Pa 1976) 6:268-273, 1981

21. Kumar MN, Baklanov A, Chopin D: Correlation between sagittal plane changes and adjacent segment degeneration following lumbar spine fusion. Eur Spine J 10:314-319, 2001

22. Lafage V, Ames C, Schwab F, Klineberg E, Akbarnia B, Smith J, et al: Changes in thoracic kyphosis negatively impact sagittal alignment after lumbar pedicle subtraction osteotomy: a comprehensive radiographic analysis. Spine (Phila Pa 1976) 37:E180-E187, 2012

23. Lafage V, Schwab F, Patel A, Hawkinson N, Farcy JP: Pelvic tilt and truncal inclination: two key radiographic parameters in the setting of adults with spinal deformity. Spine (Phila Pa 1976) 34:E599-E606, 2009

24. Lafage V, Schwab F, Vira S, Hart R, Burton D, Smith JS, et al: Does vertebral level of pedicle subtraction osteotomy correlate with degree of spinopelvic parameter correction? J Neurosurg Spine 14:184-191, 2011

25. Lafage V, Schwab F, Vira S, Patel A, Ungar B, Farcy JP: Spino-pelvic parameters after surgery can be predicted: a preliminary formula and validation of standing alignment. Spine (Phila Pa 1976) 36:1037-1045, 2011

26. Le Huec JC, Leijssen P, Duarte M, Aunoble S: Thoraco- lumbar imbalance analysis for osteotomy planification using a new method: FBI technique. Eur Spine J Suppl 5:S669S680, 2011

27. MacLennan A: Scoliosis. BMJ 2:865-866, 1922

28. Maier S, Smith JS, Schwab F, Obeid I, Mundis G, Klineberg E, et al: Revision surgery after three-column osteotomy in 335 adult spinal deformity patients: inter-center variability and risk factors. Spine (Phila Pa 1976) 39:881-885, 2014

29. Mok JM, Cloyd JM, Bradford DS, Hu SS, Deviren V, Smith JA, et al: Reoperation after primary fusion for adult spinal deformity: rate, reason, and timing. Spine (Phila Pa 1976) 34:832-839, 2009

30. Mummaneni PV, Dhall SS, Ondra SL, Mummaneni VP, Berven S: Pedicle subtraction osteotomy. Neurosurgery 63 (3 Suppl):171-176, 2008

31. Obeid I, Hauger O, Aunoble S, Bourghli A, Pellet N, Vital JM: Global analysis of sagittal spinal alignment in major deformities: correlation between lack of lumbar lordosis and flexion of the knee. Eur Spine J 20 (Suppl 5):681-685, 2011

32. Ondra SL, Marzouk S, Koski T, Silva F, Salehi S: Mathematical calculation of pedicle subtraction osteotomy size to allow precision correction of fixed sagittal deformity. Spine (Phila Pa 1976) 31:E973-E979, 2006

33. Pérennou D, Marcelli C, Hérisson C, Simon L: Adult lumbar scoliosis. Epidemiologic aspects in a low-back pain population. Spine (Phila Pa 1976) 19:123-128, 1994

34. Rillardon L, Levassor N, Guigui P, Wodecki P, Cardinne L, Templier A, et al: [Validation of a tool to measure pelvic and spinal parameters of sagittal balance.] Rev Orthop Chir Appar Mot 89:218-227, 2003 (Fr)

35. Rousseau MA, Cottin P, Levante S, Nogier A, Lazennec JY, Skalli W: In vivo kinematics of two types of ball-and-socket cervical disc replacements in the sagittal plane: cranial versus caudal geometric center. Spine (Phila Pa 1976) 33:E6E9, 2008 [Erratum in Spine (Phila Pa 1976) 33:829, 2008]

36. Rousseau MA, Lazennec JY, Tassin JL, Fort D: Sagittal rebalancing of the pelvis and the thoracic spine after pedicle subtraction osteotomy at the lumbar level. J Spinal Disord Tech 27:166-173, 2014

37. Schwab F, Blondel B, Chay E, Demakakos J, Lenke L, Tropiano $\mathrm{P}$, et al: The comprehensive anatomical spinal osteotomy classification. Neurosurgery 74:112-120, 2014

38. Schwab F, Dubey A, Gamez L, El Fegoun AB, Hwang K, Pagala M, et al: Adult scoliosis: prevalence, SF-36, and nutritional parameters in an elderly volunteer population. Spine (Phila Pa 1976) 30:1082-1085, 2005

39. Schwab F, Farcy JP, Bridwell K, Berven S, Glassman S, Harrast J, et al: A clinical impact classification of scoliosis in the adult. Spine (Phila Pa 1976) 31:2109-2114, 2006

40. Schwab F, Ungar B, Blondel B, Buchowski J, Coe J, Deinlein D, et al: Scoliosis Research Society-Schwab adult spinal deformity classification: a validation study. Spine (Phila Pa 1976) 37:1077-1082, 2012

41. Schwab FJ, Patel A, Shaffrey CI, Smith JS, Farcy JP, Boachie-Adjei O, et al: Sagittal realignment failures following pedicle subtraction osteotomy surgery: are we doing enough?: Clinical article. J Neurosurg Spine 16:539-546, 2012

42. Smith-Petersen MN, Larson CB, Aufranc OE: Osteotomy of the spine for correction of flexion deformity in rheumatoid arthritis. Clin Orthop Relat Res 66:6-9, 1969

43. Thomasen E: Vertebral osteotomy for correction of kyphosis in ankylosing spondylitis. Clin Orthop Relat Res (194):142152,1985

44. Van Royen BJ, De Gast A: Lumbar osteotomy for correction of thoracolumbar kyphotic deformity in ankylosing spondylitis. A structured review of three methods of treatment. Ann Rheum Dis 58:399-406, 1999

45. van Royen BJ, Slot GH: Closing-wedge posterior osteotomy 
for ankylosing spondylitis. Partial corporectomy and transpedicular fixation in 22 cases. J Bone Joint Surg Br 77:117121,1995

46. Vialle R, Levassor N, Rillardon L, Templier A, Skalli W, Guigui P: Radiographic analysis of the sagittal alignment and balance of the spine in asymptomatic subjects. J Bone Joint Surg Am 87:260-267, 2005

47. Yang BP, Ondra SL, Chen LA, Jung HS, Koski TR, Salehi SA: Clinical and radiographic outcomes of thoracic and lumbar pedicle subtraction osteotomy for fixed sagittal imbalance. J Neurosurg Spine 5:9-17, 2006

\section{Disclosures}

The authors report the following. Dr. Ames: employee of UCSF; consultant for Stryker, DePuy, and Medtronic; patent holder with Fish \& Richardson, PC; and royalties from Biomet Spine and Stryker. Dr. Mundis: consultant for NuVaisve and K2M; patent holder with NuVasive and K2M; clinical or research support for this study from NuVasive, DePuy Synthes, and ISSGF; and board member of SDSF, GSO, NuVasive, and Solas. Dr. Hostin: consultant for DePuy; and support of non-study-related clinical/ research effort from NuVasive, Seeger, DJO, DePuy, and K2M. Dr. Gupta: stock options in DePuy, Johnson and Johnson, Pfizer, and Pioneer. Dr. Boachie-Adjei: consultant for K2M and Weigao Co.; direct stock ownership in K2M; and grant/research support and speakers' bureau for K2M. Dr. Smith: consultant for NuVasive and Zimmer Biomet, clinical/research support for this study from DePuy Synthes and ISSG, support of non-study-related clinical/research effort from DePuy Synthes and ISSG, royalties from Zimmer Biomet, and fellowship support from NREF and AOSpine. Dr. Obeid: consultant for DePuy Synthes and Medtronic, patent holder with Alphatec Spine and Spineart, and clinical/ research support for this study from DePuy Synthes. Dr. Schwab: consultant for Medicrea, MSD, K2M, Zimmer Biomet, and NuVasive; direct stock ownership in Nemaris Inc.; patent holder with K2M and MSD; support of non-study-related clinical/research effort from SRS and DePuy Spine (paid through ISSGF); and speaking/teaching arrangements with Zimmer Biomet, K2M, Medicrea, and NuVasive. Dr. Lafage: consultant for NuVasive; direct stock ownership in Nemaris Inc.; support of non-studyrelated clinical/research effort from SRS, NIH, and DePuy Spine (paid through ISSGF); and speaking/teaching arrangements with NuVasive, DePuy Spine Synthes, Medicrea, and Nemaris Inc.

\section{Author Contributions}

Conception and design: Ferrero. Acquisition of data: Ferrero, Liabaud. Analysis and interpretation of data: Ferrero. Drafting the article: Ferrero. Critically revising the article: Henry, Ames, Kebaish, Mundis, Hostin, Boachie-Adjei, Smith, Hart, Obeid, Schwab. Reviewed submitted version of manuscript: Gupta, Diebo. Approved the final version of the manuscript on behalf of all authors: Ferrero. Statistical analysis: Ferrero. Study supervision: Ferrero, Lafage.

\section{Correspondence}

Emmanuelle Ferrero, Hôpital Européen Georges-Pompidou, 20 rue Leblanc, Paris 75015, France. email: emmanuelle.ferrero@ gmail.com. 